\title{
Prevalence and multivariable factors associated with inadvertent intraoperative hypothermia in video-assisted thoracoscopic surgery: a single-center retrospective study
}

\author{
Yinan Li, Hansheng Liang and Yi Feng ${ }^{*}$ (i)
}

\begin{abstract}
Background: Inadvertent intraoperative hypothermia increases the risk of adverse events, but its related risk factors have not been defined in video-assisted thoracoscopic surgery (VATS). This study aimed at analyzing the prevalence and factors related to inadvertent intraoperative hypothermia in adults undergoing elective VATS under general anesthesia.

Methods: This was a retrospective study using data from the Peking University People's Hospital from January through December, 2018. Data were collected on age, sex, height, weight, American Society of Anesthesiologists physical status, the duration of preparation and surgery, timing of surgery, surgery types, anesthesia types, intraoperative core temperature and the length of stay (LOS) in the hospital from the electronic database in our center. Patients were covered with a cotton blanket preoperatively and the surgical draping during the operation. A circulation-water warming mattress set to $38^{\circ} \mathrm{C}$ were placed under the body of the patients. Inadvertent intraoperative hypothermia was identified as a core temperature monitored in nasopharynx $<36^{\circ} \mathrm{C}$. Multivariate logistic regression analysis was used to identify independent risk factors of hypothermia.

Results: We found that $72.7 \%$ (95\% Cl 70.5 to $75.0 \%$ ) of 1467 adult patients who underwent VATS suffered hypothermia during surgery. The factors associated with inadvertent intraoperative hypothermia included age $(\mathrm{OR}=1.23,95 \% \mathrm{Cl} 1.11$ to $1.36, p<0.001)$, $\mathrm{BMI}(\mathrm{OR}=1.83,95 \% \mathrm{Cl} 1.43$ to $2.35, p<0.001)$, the duration of preparation $(\mathrm{OR}=1.01,95 \% \mathrm{Cl} 1.00$ to $1.02, p=0.014)$, the duration of surgery $(\mathrm{OR}=2.10,95 \% \mathrm{Cl} 1.63$ to $2.70, p<0.001)$, timing of surgery $(\mathrm{OR}=1.64,95 \% \mathrm{Cl} 1.28$ to $2.12, p<0.001)$, ambient temperature in the operating room $(\mathrm{OR}=0.67,95 \% \mathrm{Cl}$ 0.53 to $0.85, p=0.001$ ) and general anesthesia combined with paravertebral block after induction of anesthesia $(\mathrm{OR}=2.30,95 \% \mathrm{Cl} 1.31$ to $4.03, p=0.004)$. The average LOS in the hospital in the hypothermia group and the normothemic group was 9 days and 8 days, respectively $(p<0.001)$.

Conclusions: We highlight the high prevalence of inadvertent intraoperative hypothermia during elective VATS and identify key risk factors including age, duration of surgery more than $2 \mathrm{~h}$, surgery in the morning and general anesthesia combined with paravertebral block (PVB) after intubation. We also find that hypothermia did prolong the LOS in the hospital.
\end{abstract}

Keywords: Hypothermia, Video-assisted thoracoscopic surgery (VATS), Incidence, Risk factors, Paravertebral block (PVB)

\footnotetext{
* Correspondence: doctor_yifeng@sina.com

Department of Anesthesia, Peking University People's Hospital, Beijing 100044, China
}

(c) The Author(s). 2020 Open Access This article is distributed under the terms of the Creative Commons Attribution 4.0 International License (http://creativecommons.org/licenses/by/4.0/), which permits unrestricted use, distribution, and reproduction in any medium, provided you give appropriate credit to the original author(s) and the source, provide a link to the Creative Commons license, and indicate if changes were made. The Creative Commons Public Domain Dedication waiver (http://creativecommons.org/publicdomain/zero/1.0/) applies to the data made available in this article, unless otherwise stated. 


\section{Background}

Hypothermia can be divided into therapeutic hypothermia and inadvertent hypothermia. Inadvertent intraoperative hypothermia, a recognized common perioperative complication, is defined as a core temperature (Tc) $<36{ }^{\circ} \mathrm{C}$ with an incidence as high as $70 \%$ in adults undergoing elective and emergency surgery [1]. Meanwhile, hypothermia might be associated with increased risk of several different kinds of adverse events. For instance, morbid cardiac events and ventricular tachycardia, blood loss, wound infections, delayed post-anesthetic recovery time and hospitalization, and postoperative cognitive dysfunction [2-6].

Compared to open thoracic surgery, video-assisted thoracoscopic surgery (VATS) is minimally invasive and lowers the exposure of the thoracic viscera to the environment; however, VATS is still vulnerable to perioperative hypothermia [7]. Accordingly, we performed a retrospective study to determine the incidence and factors associated with inadvertent intraoperative hypothermia in adult patients during elective VATS under general anesthesia combined with paravertebral block (PVB) or not.

\section{Methods}

This single-center retrospective study was approved by the Ethical Review Committee of Peking University People's Hospital (Beijing, China) and informed consent was waived (No.2019PHB135-01). We retrieved electronic medical information from databases in our center and reviewed data from adult patients who underwent elective VATS under general anesthesia or combined with PVB in the Peking University People's Hospital from January through December, 2018. Patients < 18 years were excluded. Patients who underwent thoracotomy, laparotomy, hyperthermia intrapleural chemotherapy, emergency surgery, non-surgical or cardiac procedures, or under local anesthesia were excluded. Those lacking ambient temperature records or temperature monitoring were also excluded.

We recorded information in an electronic anesthetic documentation system certified by the Healthcare Information and Management Systems Society and rated to Electronic Medical Records Adoption Model stage 7 (HIMSS EMRAM7) in our center in 2014. Our data were all obtained from the electronic database on the server. We collected demographic data including age, sex, height and weight (used to calculate the body mass index, BMI and body surface area, BSA) and American Society of Anesthesiologists physical status (ASA). Clinical data including duration of preparation and surgery, time of surgery (morning or afternoon), types of surgery (wedge resection, lobectomy, mediastinoscopy and others), modes of anesthesia (general anesthesia or general anesthesia combined with PVB) and intraoperative core temperature were collected from the anesthetic documentation. The total time in the operating room (OR) including the preparation time from patients arriving in the OR to the start of surgery, the duration of surgery from surgical incision to the last suture, and the interval from the end of surgery to patients leaving the OR were recorded. The length of stay (LOS) in the hospital was also collected. The ambient temperature and relative humidity in the OR were obtained from the records of the hospital's control center. Patients received routine nasopharyngeal temperature monitoring as intraoperative core temperature in our study. All patients were covered with an unheated cotton blanket preoperatively and the surgical draping during operation for thermal insulation. A circulation-water warming mattress under the body of the patients was set to $38^{\circ} \mathrm{C}$ intraoperatively. We didn't use fluid warming or forced air warming device until the core temperature dropped to $35.5^{\circ} \mathrm{C}$. Inadvertent intraoperative hypothermia was defined as a core temperature (Tc) below $36^{\circ} \mathrm{C}$ during the intraoperative phase while normothemic referred to a temperature of $\mathrm{Tc} \geq 36^{\circ} \mathrm{C}$ throughout the operation. Although Our monitoring system automatically recorded the temperature data every 10 s, we collected nasopharyngeal temperature data at intervals of $5 \mathrm{~min}$, and determine the occurrence of hypothermia with all records less than $36^{\circ} \mathrm{C}$ within $5 \mathrm{~min}$ after the start of the 5 min-data less than $36^{\circ} \mathrm{C}$ in order to exclude "false" hypothermia due to factors such as equipment problems or accidental probe displacement.

Continuous variables are shown as the mean (standard deviation) in the normal distribution or the median [interquartile range] where abnormally distributed data were encountered. Frequency (percentages) distributions are shown in categorical variables. Univariate logistic regression analyses were used to explore the influencing factors for inadvertent intraoperative hypothermia, and brought variables with $p$-value less than 0.1 into multivariate logistic regression analyses with backward stepwise regression. The results were expressed as odds ratios with a 95\% confidence interval. All statistical analyses were carried out by IBM SPSS, version 22.0. A $p$-value less than 0.05 was considered statistically significant.

\section{Results}

After retrieving data from 1720 patients, 1467 were finally analyzed. The flow diagram is shown in Fig. 1 (page 17). Patients ranged 51-66 years of age (58 yrs. [51-66 yrs]), and $50.4 \%$ were overweight (BMI $\geq 24 \mathrm{~kg} / \mathrm{m}^{2}, n=740$ ). Most patients underwent lobectomy $(n=856,58.4 \%)$ and were ASA II class $(n=1113,75.9 \%)$. The mean ambient temperature and humidity was $22.6^{\circ} \mathrm{C}$ (standard deviation $0.5^{\circ} \mathrm{C}$ ) and $41 \%$ (standard deviation $9 \%$ ), respectively. PVB was widely applied in our study, with $73.6 \%$ patients $(n=$ 1079) were applied either before or after induction of anesthesia. More than half of the patients $(n=778,53 \%)$ had surgery in the morning (from 8 am to $2 \mathrm{pm}$ ) with the 


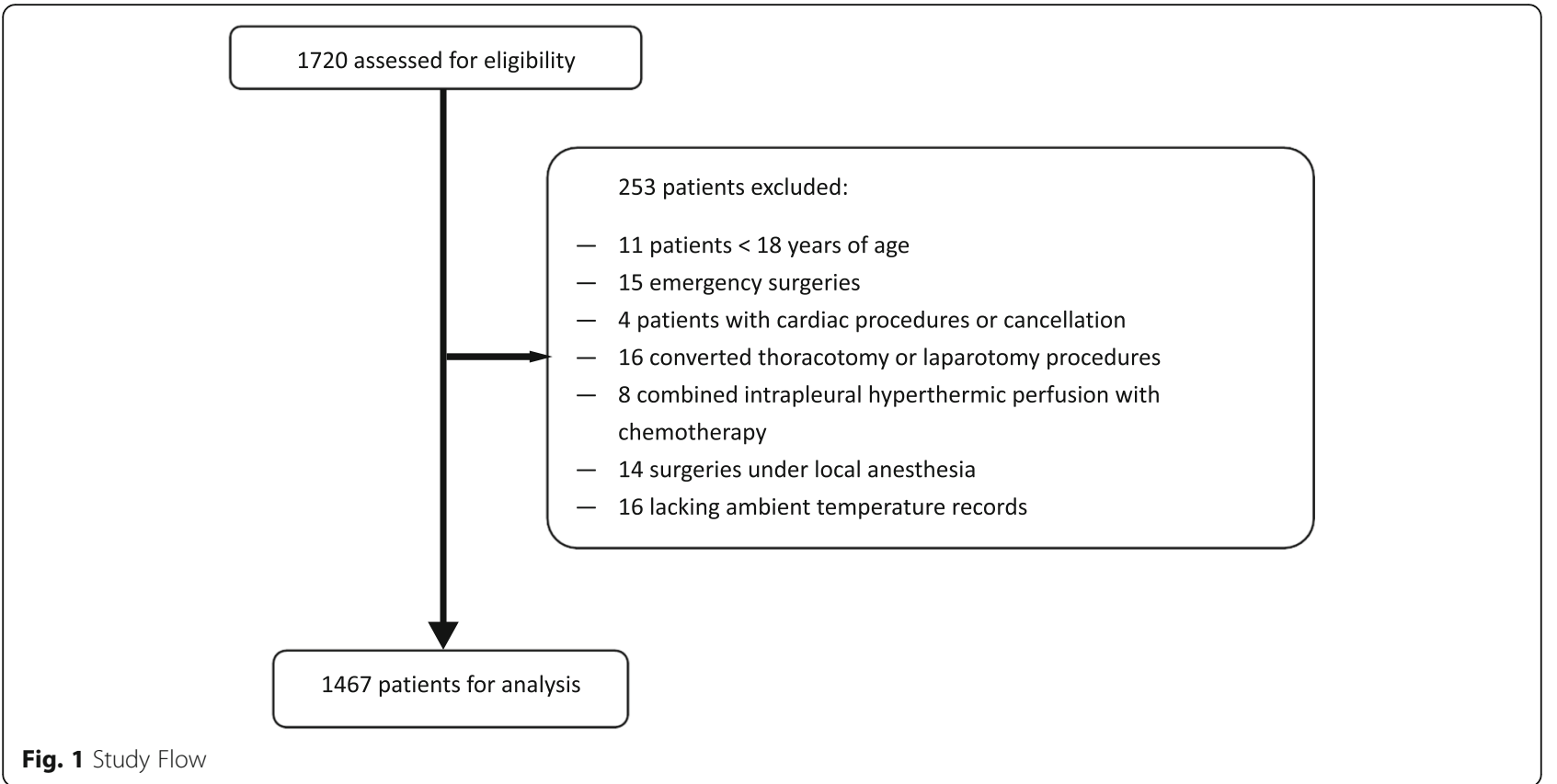

remainder having surgery in the afternoon (from $2 \mathrm{pm}$ to $8 \mathrm{pm})$. Statistical differences were observed for all variables excluding sex $(p=0.057)$ and ASA $(p=0.516)$ between the two groups. And the average LOS in the hospital in the hypothermia group and the normothemic group was 9 days and 8 days, respectively $(p<0.001)$ (Table 1 , page 13 to 14 ). Of the 1467 cases, only one in the hypothermia group died before discharge due to postoperative myocardial infarction.

Among the total population, 1067 (72.7, 95\% CI 70.5 to $75.0 \%)$ patients suffered from intraoperative hypothermia. According to the univariate logistic regression (Table 2, page $15), p$-values $\leq 0.1$ were analyzed by multivariate logistic regression, and ultimately, there were seven variables independently related to inadvertent intraoperative hypothermia (Table 3, page 16). High ambient temperature $(\mathrm{OR}=0.67$, $95 \% \mathrm{CI} 0.53$ to $0.85, p=0.001$ ) in the OR was protective against hypothermia; and age $(\mathrm{OR}=1.23,95 \% \mathrm{CI} 1.11$ to $1.36, p<0.001), \mathrm{BMI}<24 \mathrm{~kg} / \mathrm{m}^{2}$ (OR $=1.83,95 \%$ CI 1.43 to $2.35, p<0.001)$, duration of preparation $(\mathrm{OR}=1.01,95 \% \mathrm{CI}$ 1.00 to $1.02, p=0.014)$, duration of surgery more than $2 \mathrm{~h}$ $(\mathrm{OR}=2.10,95 \% \mathrm{CI} 1.63$ to $2.70, p<0.001)$, undergoing surgery in the morning $(\mathrm{OR}=1.64,95 \% \mathrm{CI} 1.28$ to $2.12, p<$ 0.001 ) and general anesthesia combined with PVB after intubation $(\mathrm{OR}=2.30,95 \% \mathrm{CI} 1.31$ to $4.03, p=0.004)$ were independent risk factors for hypothermia.

\section{Discussion}

In the current study, the prevalence of inadvertent intraoperative hypothermia in VATS was $72.7 \%$, with related risk factors including older age, longer preparation and surgery time, lower ambient temperature, receiving surgery in the morning and general anesthesia combined with PVB after intubation. Being overweight was a protective factor.

In a previous report, the overall incidence of hypothermia was $64.3 \%$ during thoracic surgery. We included a more strict definition of hypothermia $\leq 36{ }^{\circ} \mathrm{C}$ and our study cohort had a lower mean BMI than previous studies, explaining such discrepancies [8]. Being overweight is protective owing to the body fat maintaining heat balance through triggering vasoconstriction early when core temperatures decreased in obese patients [9]. Other studies divided patients into hypothermic groups at the end of surgery, which of lower incidence due to the active warming measures performed intraoperatively [10].

It was not surprised that intraoperative hypothermia is more likely to occur at an advanced age, at low room temperature, or during prolonged surgery. This was consistent with patients receiving abdominal surgery under general anesthesia [11]. Previous studies demonstrated that thermoregulatory vasoconstriction threshold is reduced in elderly patients under general anesthesia [12]. The duration of surgery was related to the decline of Tc, in agreement with the results of Suneerat et al. [13]. A longer duration of surgery results in a longer intrathoracic organ exposure time and a longer duration of anesthesia. Both general and neuraxial anesthesia could impair thermoregulatory control [14]. In this study, ambient temperatures were positively associated with core temperatures. This was in accordance with a previous study which demonstrated a higher temperature in the operating room being a strong protective factor against hypothermia [13]. However, if patients used active 
Table 1 Demographic and clinical characteristics of the patients $(n=1467)$

\begin{tabular}{|c|c|c|c|}
\hline Variable & $\begin{array}{l}\text { Hypothermia } \\
(n=1067)\end{array}$ & $\begin{array}{l}\text { Normothermia } \\
(n=400)\end{array}$ & $P$ value \\
\hline Age (yr) & $60[53-67]$ & $56[48-64]$ & $<0.001^{*}$ \\
\hline Sex & & & 0.057 \\
\hline female & $577(54.1 \%)$ & $194(48.5 \%)$ & \\
\hline male & $490(45.9 \%)$ & $206(51.5 \%)$ & \\
\hline BMI $\left(\mathrm{kg} / \mathrm{m}^{2}\right)$ & 23.81 [21.80-25.80] & 24.75 [22.68-26.89] & $<0.001^{*}$ \\
\hline$<24$ & $563(52.8 \%)$ & $164(41.0 \%)$ & \\
\hline$\geq 24$ & $504(47.2 \%)$ & $236(59.0 \%)$ & \\
\hline $\mathrm{BSA}\left(\mathrm{m}^{2}\right)$ & $1.80[1.69-1.92]$ & $1.86[1.73-2.01]$ & $<0.001^{*}$ \\
\hline$\leq 1.83$ & $626(58.7 \%)$ & $186(46.5 \%)$ & \\
\hline$>1.83$ & $441(41.3 \%)$ & $214(53.5 \%)$ & \\
\hline ASA & & & 0.516 \\
\hline 1 & $175(16.4 \%)$ & $73(18.3 \%)$ & \\
\hline$\|$ & $811(76.0 \%)$ & $302(75.5 \%)$ & \\
\hline III & $81(7.6 \%)$ & $25(6.3 \%)$ & \\
\hline $\begin{array}{l}\text { Duration of } \\
\text { Preparation (min) }\end{array}$ & $60[49-72]$ & $54[46-66]$ & $<0.001^{*}$ \\
\hline$\leq 1 \mathrm{~h}$ & $551(51.6 \%)$ & $263(65.8 \%)$ & \\
\hline$>1 \mathrm{~h}$ & $516(48.4 \%)$ & $137(34.3 \%)$ & \\
\hline Time of Surgery & & & $<0.001^{*}$ \\
\hline Morning & $616(57.7 \%)$ & $162(40.5 \%)$ & \\
\hline Afternoon & $451(42.3 \%)$ & $238(59.5 \%)$ & \\
\hline Duration of Surgery (min) & $122[94-156]$ & 100.5 [74-130] & $<0.001^{*}$ \\
\hline$\leq 2 \mathrm{~h}$ & $511(47.9 \%)$ & $267(66.8 \%)$ & \\
\hline$>2 h$ & $556(52.1 \%)$ & $133(33.3 \%)$ & \\
\hline Time in OR (min) & $201[168-237]$ & $174[140.5-210]$ & $<0.001^{*}$ \\
\hline$\leq 3 \mathrm{~h}$ & $378(35.4 \%)$ & $227(56.8 \%)$ & \\
\hline$>3 \mathrm{~h}$ & $689(64.6 \%)$ & $173(43.3 \%)$ & \\
\hline OR temperature $\left({ }^{\circ} \mathrm{C}\right)$ & $22.6[22.3-23.0]$ & $22.7[22.4-23.1]$ & $<0.001^{*}$ \\
\hline OR humidity (\%) & $40[36-51]$ & 39 [36-48] & $<0.001^{*}$ \\
\hline Type of Surgery & & & $<0.001^{*}$ \\
\hline wedge resection & $281(26.3 \%)$ & $153(38.3 \%)$ & \\
\hline lobectomy & $667(62.5 \%)$ & $189(47.3 \%)$ & \\
\hline mediastinum & $98(9.2 \%)$ & $46(11.5 \%)$ & \\
\hline others & $21(2.0 \%)$ & $12(3.0 \%)$ & \\
\hline Type of Anesthesia & & & $<0.001^{*}$ \\
\hline $\begin{array}{l}\text { general anesthesia } \\
\text { alone }\end{array}$ & $289(27.1 \%)$ & 99 (24.8\%) & \\
\hline PVB before intubation & $632(59.2 \%)$ & $283(70.8 \%)$ & \\
\hline PVB after intubation & $146(13.7 \%)$ & $18(4.5 \%)$ & \\
\hline LOS in the hospital (day) & $9[7-11]$ & $8[7-10]$ & $<0.001^{*}$ \\
\hline
\end{tabular}

Values are shown as the median [interquartile range] or number (\%), analyzed using a Mann-Whitney $\mathrm{U}$ test or chi-square test $O R$ operating room, $B M I$ body mass index, $B S A$ body surface area, $B S A=$ 0.0061 *height $(\mathrm{cm})+0.0124^{*}$ weight $(\mathrm{kg})-0.0099$; ASA American Society of Anesthesiologists physical status, PVB paravertebral block, LOS length of stay Duration of preparation refers to the interval from arrival in the $O R$ to incision

Time in the OR refers to minutes from arrival in the $O R$ to leaving the $O R$ warming strategies such as forced-air blankets, the effects of intraoperative ambient temperatures on hypothermia were mild [15].

A significant finding of this retrospective study was that the data analysis showed timing of surgery or paravertebral block were also important factors influencing intraoperative hypothermia. Compared to surgery performed in the afternoon, the risk of intraoperative hypothermia was 1.6 fold higher than in the morning. This may be due to the epigenetic clock function in body temperature as reported in different seasons in a previous study. According to a study investigating individual body temperature, diurnal variation in temperature peak at $4 \mathrm{pm}$ compared to 12 pm [16]. Furthermore, those undergoing surgery in the afternoon provide perioperative myocardial protection [17]. Hence, it is beneficial to perform surgery in the afternoon compared to in the morning to regarding in reduction of reduce the occurrence of hypothermia.

This is the first documented report to establish relationships between PVB and hypothermia. There were no statistical differences between general anesthesia with PVB and general anesthesia alone related to hypothermia in univariate logistic regression. According to the blocking time, ultrasound-guided PVB was further divided into the preinduction PVB group and the post-induction PVB group. Patients who received ultrasound-guided PVB first and then underwent general anesthesia were referred to as preinduction PVB, while patients who received ultrasoundguided PVB after general anesthesia were referred to as post-induction PVB. After regrouping PVB according to blocking time, compared with general anesthesia alone, the risk of intraoperative hypothermia was 2.3 fold higher in patients undergoing general anesthesia combined with post-induction PVB by multivariate logistic regression analysis. Compared to the epidural anesthesia (EA), PVB blocks ipsilateral sympathetic nerves and is associated with a reduction in hypotension [18]. As known, EA leads to hypothermia through its ability to redistribute heat [19]. PVB may therefore promote hypothermia through the same mechanism. However, it may have a "hypothermic preconditioning" function which differs from EA due to its unilateral sympathetic block. PVB may neutralize variations in Tc by enhancing thermogenesis before general anesthesia impairing thermoregulatory control. Further randomized controlled studies are required to establish the relationship between PVB and hypothermia.

There were some limitations in this study. First, only the relationship between hypothermia and variations were analyzed but the etiology associated was not discussed. Then, the core temperature data of PACU cannot be obtained retrospectively, so we did not analyze the correlation between intraoperative core temperature and PACU temperature. And a further limitation was the study being single-centered, limiting its external validity. 
Table 2 Univariate logistic regression for inadvertent intraoperative hypothermia rates

\begin{tabular}{|c|c|c|c|c|c|c|}
\hline \multirow[b]{2}{*}{ Age (per decade) } & \multirow{2}{*}{$\frac{\beta}{.256}$} & \multirow{2}{*}{$\frac{\text { Wald }}{27.188}$} & \multirow{2}{*}{$\frac{\text { Odds ratio }}{1.292}$} & \multicolumn{2}{|c|}{ 95\% confidence interval } & \multirow{2}{*}{$\frac{P \text { value }}{.000^{*}}$} \\
\hline & & & & 1.173 & 1.423 & \\
\hline Female & .223 & 3.623 & 1.250 & .993 & 1.574 & .057 \\
\hline BMI $\left(\mathrm{kg} / \mathrm{m}^{2}\right)$ & -.100 & 26.662 & .905 & .871 & .940 & $.000^{*}$ \\
\hline$<24$ & .475 & 15.985 & 1.607 & 1.274 & 2.029 & $.000^{*}$ \\
\hline $\mathrm{BSA}\left(\mathrm{m}^{2}\right)$ & -2.101 & 36.946 & .122 & .062 & .241 & $.000^{*}$ \\
\hline$\leq 1.83$ & .491 & 17.293 & 1.633 & 1.296 & 2.058 & $.000^{*}$ \\
\hline \multicolumn{7}{|l|}{ ASA } \\
\hline । & / & 1.319 & / & / & / & .517 \\
\hline$\|$ & .114 & .538 & 1.120 & .827 & 1.517 & .463 \\
\hline III & .301 & 1.265 & 1.352 & .799 & 2.285 & .261 \\
\hline Duration of Preparation (min) & .019 & 23.995 & 1.019 & 1.012 & 1.027 & $.000^{*}$ \\
\hline$>1 \mathrm{~h}$ & .587 & 23.160 & 1.798 & 1.416 & 2.283 & $.000^{*}$ \\
\hline Surgery in the morning & .696 & 34.122 & 2.007 & 1.588 & 2.535 & $.000^{*}$ \\
\hline Duration of Surgery (min) & .009 & 45.492 & 1.009 & 1.007 & 1.012 & $.000^{*}$ \\
\hline$>2 \mathrm{~h}$ & .781 & 40.642 & 2.184 & 1.718 & 2.777 & $.000^{*}$ \\
\hline Time in OR (min) & .008 & 46.178 & 1.008 & 1.006 & 1.010 & $.000^{*}$ \\
\hline$>3 h$ & .872 & 53.239 & 2.392 & 1.892 & 3.023 & $.000^{*}$ \\
\hline OR temperature $\left({ }^{\circ} \mathrm{C}\right)$ & -.388 & 11.685 & .678 & .543 & .847 & $.001^{*}$ \\
\hline OR humidity (\%) & .026 & 11.132 & 1.026 & 1.011 & 1.042 & $.001^{*}$ \\
\hline \multicolumn{7}{|l|}{ Type of Surgery } \\
\hline lobectomy & / & 28.149 & / & / & / & .000 \\
\hline wedge resection & -.653 & 25.264 & .520 & .403 & .671 & $.000^{*}$ \\
\hline mediastinum & -.505 & 6.577 & .604 & .410 & .888 & $.010^{*}$ \\
\hline others & -.701 & 3.572 & .496 & .240 & 1.026 & .590 \\
\hline \multicolumn{7}{|l|}{ Type of Anesthesia } \\
\hline general anesthesia alone & / & 26.221 & / & / & / & .000 \\
\hline PVB before intubation & -.268 & 3.842 & .765 & .585 & 1.000 & $.050^{*}$ \\
\hline PVB after intubation & 1.022 & 13.747 & 2.779 & 1.619 & 4.769 & $.000^{*}$ \\
\hline
\end{tabular}

$B M I$ body mass index, BSA body surface area, BSA $=0.0061^{*}$ height $(\mathrm{cm})+0.0124^{*}$ weight $(\mathrm{kg})-0.0099 ;$ ASA American Society of Anesthesiologists physical status, OR operating room, PVB paravertebral block

Time in OR refers to minutes from arrival in OR to leaving OR

Table 3 Multivariate logistic regression for inadvertent intraoperative hypothermia rates

\begin{tabular}{|c|c|c|c|c|c|c|}
\hline \multirow[b]{2}{*}{ Age (per decade) } & \multirow{2}{*}{$\frac{\beta}{.206}$} & \multirow{2}{*}{$\begin{array}{l}\text { Wald } \\
15.898\end{array}$} & \multirow{2}{*}{$\begin{array}{l}\text { Adjusted odds ratio } \\
1.229\end{array}$} & \multicolumn{2}{|c|}{ 95\% confidence interval } & \multirow{2}{*}{$\frac{P \text { value }}{.000^{*}}$} \\
\hline & & & & 1.111 & 1.360 & \\
\hline $\mathrm{BMl}<24 \mathrm{~kg} / \mathrm{m}^{2}$ & .606 & 23.351 & 1.833 & 1.434 & 2.345 & $.000^{*}$ \\
\hline Surgery in the morning & .497 & 14.915 & 1.644 & 1.278 & 2.117 & $.000^{*}$ \\
\hline Duration of Preparation (min) & .010 & 5.995 & 1.011 & 1.002 & 1.019 & $.014^{*}$ \\
\hline Duration of Surgery $>2 \mathrm{~h}$ & .742 & 33.426 & 2.099 & 1.633 & 2.699 & $.000^{*}$ \\
\hline OR temperature $\left({ }^{\circ} \mathrm{C}\right)$ & -.401 & 11.243 & .670 & .530 & .847 & $.001^{*}$ \\
\hline \multicolumn{7}{|l|}{ Type of Anesthesia } \\
\hline general anesthesia alone & / & 10.797 & / & / & / & .005 \\
\hline PVB before intubation & -.084 & .309 & .920 & .685 & 1.235 & .579 \\
\hline PVB after intubation & .832 & 8.441 & 2.298 & 1.311 & 4.029 & $.004^{*}$ \\
\hline
\end{tabular}

Method = Backward Stepwise (Likelihood Ratio)

$B M I$ body mass index, OR operating room, $P V B$ paravertebral block

${ }^{*} p$-value less than 0.05 was considered statistically significant 


\section{Conclusions}

The prevalence of inadvertent intraoperative hypothermia in adult patients during elective VATS under general anesthesia is high. And we find that hypothermia did prolong the length of stay. Being overweight prevented patients from hypothermia, while independent risk factors associated with hypothermia were old age, a duration of surgery more than $2 \mathrm{~h}$, morning surgery and general anesthesia combined with PVB after intubation. Advanced prospective studies are now required evaluate the relationship between PVB and inadvertent intraoperative hypothermia.

\begin{abstract}
Abbreviations
ASA: American Society of Anesthesiologists physical status; BMI: Body mass index; EA: Epidural anesthesia; HIMSS EMRAM7: the Healthcare Information and Management Systems Society and rated to Electronic Medical Records Adoption Model stage 7; OR: Operating room; PVB: Paravertebral block; Tc: Core temperature; VATS: Video-assisted thoracoscopic surgery
\end{abstract}

\section{Acknowledgements}

We thank Xu Guo for his designing of data retrieval program, Huixin Liu and Xiaohua Zhou for their statistical consultation, and Kehong Zhang for his scientific writing instruction, sincerely.

\section{Authors' contributions}

All authors designed the study and revised the manuscript. YL conducted the study, collected and analyzed the data, and drafted the manuscript. HL and YF made contributions to the conception of the work and substantively revised the manuscript. All authors read and approved the final manuscript.

\section{Funding}

This study was supported by the National Key Research and Development Program of China (Grant No.2018YFC2001905).

\section{Availability of data and materials}

The datasets used and analysed during the current study are available from the corresponding author on reasonable request.

\section{Ethics approval and consent to participate}

This study was approved by the Ethical Review Committee of Peking University People's Hospital (Beijing, China) and informed consent was waived (No.2019PHB135-01).

\section{Consent for publication}

Not applicable.

\section{Competing interests}

The authors declare that they have no competing interests.

Received: 12 November 2019 Accepted: 23 January 2020

Published online: 28 January 2020

\section{References}

1. NICE: The Management of Inadvertent Perioperative Hypothermia in Adults Vol. NICE Clinical Guideline 65. 2008.

2. Frank SM. Perioperative maintenance of normothermia reduces the incidence of morbid cardiac events. JAMA. 1997;277(14):1127.

3. Schmied H, Reiter A, Kurz A, Sessler DI, Kozek S. Mild hypothermia increases blood loss and transfusion requirements during total hip arthroplasty. Lancet. 1996:347(8997):289-92.

4. Lenhardt R, Marker E, Goll V, Tschernich H, Kurz A, Sessler DI, Narzt E, Lackner F. Mild intraoperative hypothermia prolongs Postanesthetic recovery. Anesthesiology. 1997;87(6):1318-23.

5. Kurz A, Sessler DI, Lenhardt R. Perioperative Normothermia to reduce the incidence of surgical-wound infection and shorten hospitalization. N Engl J Med. 1996;334(19):1209-16.
6. Ma H, Lai B, Dong S, Li X, Cui Y, Sun Q, Liu W, Jiang W, Xu F, Lv H, et al. Warming infusion improves perioperative outcomes of elderly patients who underwent bilateral hip replacement. Medicine. 2017;96(13):e6490.

7. Franke R, Brandes I, Hinterthaner M, Danner B, Bauer M, Bräuer A, Emmert A Comparison of conductive and convective warming in patients undergoing video-assisted thoracic surgery: a prospective randomized clinical trial. Thorac Cardiovasc Surg. 2016;65(05):362-6.

8. Emmert A, Gries G, Wand S, Buentzel J, Bräuer A, Quintel M, Brandes IF. Association between perioperative hypothermia and patient outcomes after thoracic surgery. Medicine. 2018;97(17):e0528.

9. Kasai T, Hirose M, Matsukawa T, Takamata A, Tanaka Y. The vasoconstriction threshold is increased in obese patients during general anaesthesia. Acta Anaesthesiol Scand. 2003;47(5):588-92.

10. Sumida H, Sugino S, Kuratani N, Konno D, J-i H, Yamauchi M. Effect of forced-air warming by an underbody blanket on end-of-surgery hypothermia: a propensity score-matched analysis of 5063 patients. BMC Anesthesiol. 2019;19(1):50.

11. Kim EJ, Yoon H. Preoperative factors affecting the intraoperative Core body temperature in abdominal surgery under general anesthesia. Clin Nurse Spec. 2014;28(5):268-76.

12. Ozaki M, Sessler DI, Matsukawa T, Ozaki K, Atarashi K, Negishi C, Suzuki $H$. The threshold for thermoregulatory vasoconstriction during nitrous oxide/sevoflurane anesthesia is reduced in the elderly. Anesth Analg. 1997:84(5):1029-33.

13. Kongsayreepong S, Chaibundit C, Chadpaibool J, Komoltri C, Suraseranivongse S, Suwannanonda P, Raksamanee E-o, Noocharoen P Silapadech A, Parakkamodom S, et al. Predictor of Core hypothermia and the surgical intensive care unit. Anesth Analg. 2003;93:826-33.

14. Sessler DI. Perioperative thermoregulation and heat balance. Lancet. 2016; 387(10038):2655-64

15. Pei L, Huang $Y, X u$ Y, Zheng Y, Sang X, Zhou X, Li S, Mao G, Mascha EJ, Sessler DI. Effects of ambient temperature and forced-air warming on intraoperative core temperature. Anesthesiology. 2018;128(5):903-11.

16. Obermeyer Z, Samra JK, Mullainathan S. Individual differences in normal body temperature: longitudinal big data analysis of patient records. BMJ. 2017;359:j5468.

17. Montaigne D, Marechal X, Modine T, Coisne A, Mouton S, Fayad G, Ninni S, Klein C, Ortmans S, Seunes C, et al. Daytime variation of perioperative myocardial injury in cardiac surgery and its prevention by rev-Erba antagonism: a single-Centre propensity-matched cohort study and a randomised study. Lancet. 2018;391(10115):59-69.

18. Davies RG, Myles PS, Graham JM. A comparison of the analgesic efficacy and side-effects of paravertebral vs epidural blockade for thoracotomy-a systematic review and meta-analysis of randomized trials. $\mathrm{Br} J$ Anaesth. 2006;96(4):418-26

19. Glosten B, Hynson J, Sessler DI, McGuire J. Preanesthetic skin-surface warming reduces redistribution hypothermia caused by epidural block. Anesth Analg. 1993;77(3):488-93.

\section{Publisher's Note}

Springer Nature remains neutral with regard to jurisdictional claims in published maps and institutional affiliations.
Ready to submit your research? Choose BMC and benefit from:
- fast, convenient online submission
- thorough peer review by experienced researchers in your field
- rapid publication on acceptance
- support for research data, including large and complex data types
- gold Open Access which fosters wider collaboration and increased citations
- maximum visibility for your research: over $100 \mathrm{M}$ website views per year
At BMC, research is always in progress.
Learn more biomedcentral.com/submission 